\title{
IGREJA ASSEMBLEIA DE DEUS DO BRASIL DE CORUMBÁ: UMA IGREJA ATUANTE NA REGIÃO DO PANTANAL
}

\section{ARTIGO ORIGINAL \\ OLIVEIRA, Marcelo Soares de ${ }^{1}$}

GOMES, Kleber ${ }^{2}$

OLIVEIRA, Marcelo Soares de. GOMES, Kleber. Igreja Assembleia de Deus do Brasil de Corumbá: Uma igreja atuante na região do Pantanal. Revista Científica Multidisciplinar Núcleo do Conhecimento. Ano 05, Ed. 03, Vol. 10, pp. 168-181. Março de 2020. ISSN: 2448-0959, Link de acesso: https://www.nucleodoconhecimento.com.br/teologia/assembleia-de-deus

\section{RESUMO}

O objetivo deste artigo é descrever um breve histórico da Igreja Evangélica Assembleia de Deus em Corumbá e seu papel de relevância na região. Destaca-se o fato que o trabalho se iniciou em Corumbá-MS em 1941, e no decorrer da trajetória este ministério se fez presente na região com ampliação da obra e atividades assistenciais. As fontes de pesquisas utilizadas foram os livros atas, documentação do memorial da igreja, entrevista realizada com pastor presidente em exercício e além de sites. Foi realizada uma pesquisa qualitativa de dados, através da análise bibliográfica dos materiais da igreja e entrevista. Este material poderá servir como fonte de consulta para os futuros estudantes o artigo não esgota o tema em questão, mas aborda de maneira resumida o papel histórico da Igreja.

Palavras-chave: Almas, assistência, ensino.

1 Pós-Graduado (Lato Sensu) Diálogo Inter-Religioso (UNIGRA-MS), Bacharel em Teologia (ENTRE RIOS-PI) e Bacharel em Administração (UFMS-MS).

${ }^{2}$ Mestre em Teologia. 


\section{INTRODUÇÃO}

O artigo abordará a influência e um sucinto histórico da Igreja Evangélica Assembleia de Deus no Brasil em Corumbá-MS, para a região do pantanal e a fronteiriça (BRASILBOLIVIA)[3], bem como sua importância. Sua história originou-se através do compromisso com chamado visionário de dois jovens missionários suecos que tiveram o contato com o avivamento da Rua Azusa nos EUA que na época mudaram as suas vidas ao receberem o batismo no Espírito Santo e os dons espirituais.

Os dois jovens Gunnar Vingren e Daniel Berg por inspiração do Espírito Santo receberam a profecia de irem para Belém no Pará no Brasil e em obediência deslocaram para Nova York e encontraram, o navio Clement, que fora tido em sonho profético o nome do mesmo, e assim, sairiam em 05 de novembro de 1910 para o Brasil. Por falta de dinheiro, adquirirão uma passagem de terceira classe e viajaram para o Brasil desembarcando depois de duas semanas em Belém do Pará, não conhecia a língua do país, mas desejosos em levar a palavra do Senhor.

Os missionários desembarcaram em Belém, capital do Estado do Pará, no dia 19 de novembro de 1910. Depois de alguns meses trabalhando na obra missionária no Brasil fundam em 18 de junho de 1911 a igreja que revolucionária o perfil religioso e social do país, através da pregação da palavra de Deus falando de um Jesus batiza no Espírito Santo e reparte os dons espirituais para igreja. A Importância da Igreja Evangélica Assembleia de Deus do Brasil na Região do Pantanal, deve-se a relevância da grande comissão inferida pelo Senhor Jesus no livro de Marcos Cap. 16 Vers. 15 (ALMEIDA, Bíblia Sagrada, 1996). Exatamente através dessa grande comissão de levar a palavra a todos os cantos da terra que os missionários aportaram no Brasil com propósito de ganharem as almas.

Nesta visão de levar a palavra de Deus até os confins da terra que foi criada a igreja evangélica Assembleia de Deus do Brasil na cidade de Corumbá-MS e através do compromisso dos pastores que lutaram incansavelmente para o crescimento da obra, e ela é a mais antiga igreja das Assembleias de Deus da região, pois foi fundada em 1941 e respectivamente as cidades de Cuiabá-MT e Campo Grande-MS as capitais 
foram fundadas em 1944, este relato histórico é de fundamental importância para a história como a primeira igreja de Mato Grosso e respectivamente hoje, Mato Grosso do Sul que assim se tornou após a divisão do estado em 11 de outubro de 1977[4].

De fato, é relevante o papel da igreja na região e podemos relatar que o compromisso em levar a palavra do Senhor, fez com que expandisse na região indo até o país vizinho Bolívia, dentre toda esta dimensão temos vários fatores que fizeram dela uma igreja visionaria estendendo para outras terras, onde se encontra dezenas de missionários realizando o trabalho da evangelização. A Assembleia de Deus do Brasil em Corumbá está presente desde 1941 e tem atuado em várias áreas dentre quais podemos destacar a principal a pregação da palavra do Senhor, assistência social e escolar. Tem sido difundido seu trabalho em toda região conforme visto sobre toda a assistência aos ribeirinhos do pantanal.

A igreja mantém uma cooperação com entidades governamentais, igrejas e ONGs que participam de trabalhos assistenciais para os ribeirinhos do Rio Paraguai e ainda tem intercambio com irmãos norte-americanas que vieram convidadas pelo intermédio da Eetad, em Campinas-SP. Os quais trazem profissionais da área da saúde que dedicam seus tempos e serviço a obra do mestre Jesus no Pantanal, e assim, realizando um trabalho de assistência a comunidade mais afastada através dos barcos Bom Pastor I e II chegam aos necessitados da região ribeirinha, tendo o cuidado no atendimento médico, odontológico, assistencial e espiritual realizando um trabalho importante e os irmãos da igreja dos Estados Unidos da América veem em períodos para realizarem este trabalho assistencial.

Ainda, a igreja tem uma escola evangélica em prédio próprio, com capacidade em ser transformada em um Centro Educacional. Surgiu um projeto da Assembleia de Deus, com várias salas, auditório para duzentas pessoas sentadas, sala de projeção, secretaria, biblioteca e etc. Em 04 de maio de 2002 começou o desafio para construção deste novo complexo e a escola passa por uma reestruturação e atende, hoje, criança do ensino jardim e pré-escola, por medidas orçamentárias a escola não tem atendido o ensino fundamental e médio, mas logo será restruturada para o ensino escolar regulamentar. 
A Escola Evangélica é firmada nos princípios morais, éticos da família e ensino bíblico da palavra do Senhor, aonde as crianças aprendem a darem valor à palavra de Deus, apesar de todas as dificuldades enfrentadas, desde quando fora criada a Escola de $1^{\circ}$ grau Assembleia de Deus, que iniciou seu funcionamento no dia 3 de fevereiro de 1977, e está completando seus 40 anos de existência de trabalho na região pantaneira.

Em 30 de janeiro de 1975 fora criado na presidência do Pastor Carlos Padilha de Siqueira o Serviço de Assistência Social e Cultura da Igreja Evangélica Assembleia de Deus - SASC que coordena todo trabalho assistencial e cultural da igreja, visa atender os necessitados, bem como os serviços assistenciais do barco Bom Pastor e outros serviços realizados pela igreja.

Temos ainda a expansão para o país vizinho aonde a igreja sustenta missionários na Bolívia, grande movimento tem acontecido e isto fez com que se ampliassem as igrejas na fronteira do Brasil.

Hoje, a sede dispõe de um templo reestruturado com capacidade estendida para cinco mil pessoas, e ainda está sendo realizadas algumas finalizações na construção, com estacionamento coberto, banheiros novos, salas novas dentre outras melhorias. A igreja tem aumentado os números de congregações na região, obtendo um crescimento em número de irmão e irmãs, as novas congregações estão espalhadas por toda área urbana e rural, bem como no país vizinho.

\section{HISTÓRICO E A RELEVÂNCIA DA IGREJA EVANGÉLICA ASSEMBLEIA DE DEUS EM CORUMBÁ}

\subsection{FORMAÇÃO DA IGREJA E SEU HISTÓRICO}

A Igreja Evangélica Assembleia de Deus em Corumbá como já relatado é a igreja da AD mais antiga do Estado, seu crescimento se deu pelo compromisso dos servos do Senhor com a Palavra de Deus, na evangelização e na construção de templos. No início o trabalho foi realizado de forma árdua e humilde a pé, de casa em casa entre 
outros meios. A expansão da igreja ocorreu através de muita labuta dos homens e mulheres valorosos, que não mediram esforços e suas próprias vidas para divulgarem o evangelho do Senhor Jesus na região. Muitos irmãos contribuíram, contudo não temos todos os nomes, mas existem nos registros da Igreja a referência de alguns irmãos e irmãs que tiveram papel importante e encontram-se gravados nos anais da história da igreja, pois se dispuseram a realizarem um trabalho de excelência para a construção e desenvolvimento da obra na região.

A igreja foi fundada em 1941 e posteriormente as capitais de Cuiabá-MT e Campo Grande-MS que foram estabelecidas em 1944, este relato histórico da data de fundação da igreja $A D$ de Corumbá é relevante, por ser a primeira igreja $A D$ em Mato Grosso e, hoje a igreja é do Estado de Mato Grosso do Sul, por causa da divisão do estado que ocorreu em 11 de outubro de 1977, ao qual o presidente da época criou o estado de Mato Grosso do Sul. Portanto, muitos relatos e acontecimentos da igreja têm vínculo com o estado de Mato Grosso, cuja capital atual é a cidade de Cuiabá, de fato, todo trabalho realizado teve suporte dos pastores oriundos da região matogrossense.

Nos anos de 1941, foi a data que iniciou os trabalhos da igreja em Corumbá quando Eduardo Joerck e João Rodrigues que se dispuseram a evangelizar os habitantes da região e logo fundando na época a congregação que se localizava-se na rua Delamare. O Irmão Joerck muda-se para Cuiabá e deixa à frente da congregação Tomas Lindores que vindo da igreja Neo Testamentária. Porém a igreja tem a base pentecostal da $A D$, e o irmão Pedro Ferreira foi o primeiro membro batizado no Espírito Santo. Em 1943, o Pastor Cicero Canuto envia o pastor Vital de Oliveira para Corumbá (Memorial, 2005), neste período a congregação reunia na Rua João Pessoa, atual Rua Dom Aquino, foi quando instituiu o nome igreja Evangélica Assembleia de Deus.

Fato importante foi que no ano de 1945, chegou o Pastor Daniel Beltrão que mudou o endereço para rua 13 de junho, № 1987, a congregação localizava-se próximo casa do Pr. Francisco Faria que é o membro mais antigo da igreja existente, o mesmo foi batizado em águas, em 14 de agosto de 1946, a congregação permaneceu neste endereço até 1951. 
Foi no ano de 1949 quando o Pr. Antônio Domingos Martins que a congregação começou a iniciar o trabalho com Círculo de Oração e o Coral da igreja. Nesta gestão que a igreja comprou o terreno da Rua Cabral, onde construiu o primeiro Templo da Igreja medindo $10 \mathrm{~m} \times 7 \mathrm{~m}$ e assim foi iniciado o trabalho em Corumbá. Hoje a sede encontra-se neste mesmo endereço, porém com templo maiores dimensões e várias outras infraestruturas realizadas entorno da igreja.

E foi em 1953, que a igreja expandiu na Bolívia o Pr. Farias naquele momento interinamente na presidência da igreja aluga espaço em Porto Soares, para funcionar a Congregação Boliviana, sobe direção dos irmãos em Corumbá. Vale ressaltar que muitos pastores passaram na direção da igreja destes líderes destacam-se alguns que puderam expandir os trabalhos. Em 1962, na direção do Pastor Manoel L. Bezerra o templo foi ampliado, construção do porão e a construção de congregações em Ladário, Itaú, Alameda Boa Esperança e Popular Nova, este líder permaneceu doze anos na presidência (Memorial da Assembleia de Deus de Corumbá 64 anos, 2005).

Entretanto, no pastoreado que a evangelização cresceu na Bolívia. Fundou a igreja em Puerto Quijarro, e o pastor Túlio de Barros[5] estava presente a igreja é supervisionada pelo ministério de Corumbá. Depois foi inaugurada a congregação em Porto Soares e assim por diante a missão foi estendida entorno da malha ferroviária que corta a Bolívia.

Em 1974, o Pastor Carlos Padilha Assume a presidência e já nos primeiros dias adquire o terreno e começa a construção de um novo templo. Foi em 30 de janeiro de 1975, que criarão o Serviço de Assistência Social e Cultura da Igreja Evangélica Assembleia de Deus - SASC[6]. O SASC reuniu para fundar uma Escola Evangélica da Assembleia de Deus, que iniciou o trabalho em 03 de fevereiro de 1977 através de muito esforço dos irmãos o trabalho crescia de forma que o Senhor sustentava a igreja dando suporte para crescimento.

O serviço do SASC visa atender os membros mais necessitados e esse papel foi relevante para construção de valores humanitários da assistência ao que é mais importante as pessoas. Também foi adquirido a Rádio Atalaia que transmitia os cultos 
ao vivo e além de divulgar os trabalhos da igreja com uma programação evangélica. Em 1977 finaliza-se o término da construção do templo e assim inaugurado.

No ano 1985 foi transferido pastor Padilha e transfere a direção para o Pastor Carlos Gomes Galvani que por sua vez transfere em 1987 para o Pastor Manoel Luiz Bezerra e tiveram outros pastores que ficaram a frente por pouco tempo, mas vale ressaltar alguns que foram relevantes para o ministério.

Foi no ano de 1990 que o Pastor José Wellington B. Costa empossa o Pastor Dirceu Mariano para presidência e este por sua vez passa direção para o Pastor João Martins em 18 de junho de 1996, que é o atual pastor da igreja e quem dá a posse é o Pastor Antônio Dionízio da Silva.

O pastor chegou em Corumbá, com esposa a Missionária Eva Martins e filhos, João Lucas Martins que é o atual vice-presidente da igreja e a irmã Keila Rebeca, e assim inicia o trabalho do Pastor João em terras pantaneiras.

O Pastor João Martins começa logo a construção do refeitório da igreja, também segundo relato do pastor, alguns anos atrás quando estava na diretoria da Secretaria de Missões do Estado, desejava colocar em funcionamento barco para atendimento dos ribeirinhos e quando assumiu a igreja de Corumbá colocou em prática o desejo de anos que houvera e da secretária de missões do estado para aquisição de barco para atendimento ribeirinho e assim, foi em 1998 inaugurou o Barco Bom Pastor e com a presença de muitas autoridades e a igreja AD Corumbá se consolida junto à sociedade corumbaense em prol da assistência humanitária aos menos favorecidos e também o atendimento espiritual aos ribeirinhos.

A Igreja Evangélica Assembleia de Deus Ministério de Belém de Corumbá está completando neste ano de 2017 seus 76 anos de trabalho na região do pantanal uma igreja comprometida com a obra do Senhor que durante toda sua caminhada esteve imbuída com a pregação do evangelho e tem crescido de maneira vertiginosa. Atualmente é o maior templo da Assembleia de Deus do estado de Mato Grosso do 
sul, através da visão da liderança que se mobilizaram para ampliação de um novo templo com capacidade para 5 mil membros.

O trabalho da igreja está espalhada na área urbana, rural e também na Bolívia por esse motivo a preocupação de um templo maior que possa comportar todos os membros da igreja. Relevante a atuação deste ministério que preocupado com crescimento da palavra e assistência aos membros e sociedade da região do pantanal.

Diante a todos os fatos da criação e desenvolvimento deste Ministério Evangélico pode ser verificado que todo esforço esmerado até agora de suas conquistas é fruto de muito trabalho, dedicação dos fundadores e todos líderes que passaram pela igreja. O grande compromisso da AD[7] de Corumbá com a Evangelização, Assistência Social, Assistência Médica, Atendimento aos Ribeirinhos, Ensino Evangélico e a todo trabalho realizado, demonstram que a igreja é atuante na região como uma referência para outros Ministérios Evangélicos, por este exposto acima fez se necessário relatar seu histórico como uma igreja presente que também não se resume, apenas aos fatos exposto no trabalho.

Podemos relatar alguns testemunhos que ocorreram e que marcaram o trabalho no barco, segundo Pastor João Martins: "Relatou que o barco ficou impedido de sair de uma localidade por três dias e nessa ocasião tinha um rapaz que estava muito mal que nem andava e falava, durante esses dias que ficaram o Senhor o curará e o salvará saindo do barco glorificando a Deus" (MARTINS, 2017). Ainda o barco teve outro fato que deixou todos maravilhados que relataram que uma dentista voluntária que venho de São Paulo para trabalhar no barco e durante a viagem realizou todo seu trabalho assistencial aos ribeirinhos e quando voltavam e já no último dia para chegarem em Corumbá a dentista pergunta ao pastor que precisava para ela aceitar a Jesus Cristo? Então ali, mesmo no barco ela aceitará ao Senhor e todos se alegraram e louvaram a Deus.

O Centro Educacional foi inaugurado no dia 18 de julho de 2004, tivera a presença de várias autoridades Eclesiásticas e Governamentais. O trabalho realizado para glória 
do Senhor pela igreja aconteceu através de muita dedicação dos irmãos e participações de outras instituições que ajudaram permitindo a conclusão desta obra.

A igreja, hoje por motivo orçamentário ocasionado pela inadimplência por parte dos pais de alunos mantém somente o ensino infantil na escola evangélica, em vista também que está ocorrendo no país da crise que alcançou as famílias e também da perda da parceria que tinha com a prefeitura de Corumbá. A igreja optou em reformular, e assim, ficando apenas com ensino infantil, que poderá futuramente voltar com ensino fundamental e médio.

Este evento marcou a igreja de Corumbá que na sequência, sob a liderança do Pr. João Martins, no dia 14 de agosto de 2004 é iniciada a primeira etapa da construção, em sistema de mutirão com membros da Igreja. A construção do hospital ocorrerá depois de várias Ações Sociais e Clínicas Médicas que foram realizadas em parcerias com o Hospital Evangélico de C.Grande, Exército Brasileiro, Fundação Health Care Ministries (Min. Bernhard Jhonson)[8], Secret. de Assist. Social e Saúde de Corumbá e Ladário.

O hospital encontra-se fechado por motivos de profissionais que dispõem para fazer serviço voluntário, mas a igreja realiza de forma periódica atendimento através de ações sociais que em parceria muitas das vezes com Exército e outros poderes públicos para poder fazer atendimento médico à população da região. A igreja tem toda infraestrutura para poder funcionar o hospital infelizmente por meios próprios não tem condições de manter em funcionamento necessitando da ajuda do governo e por motivos políticos o hospital não pode estar em funcionamento, igreja tentará vários acordos com poder públicos infelizmente sem adquirir êxito e por enquanto encontrase fechado.

O início da obra evangelística em Corumbá aplicada pelos seus pioneiros foi usada uma maneira simples e consagrada de levar a palavra, todos os irmãos alcançados tiveram um encontro com Senhor, onde a palavra era que Jesus Salva e Batiza no Espírito Santo como os pioneiros faziam distribuindo material evangelístico para todas as almas alcançadas. 
Os pastores que passaram tiveram o compromisso de firmar a igreja com a palavra de Deus e ensino tanto é que completa este ano sua 71르 Escola Bíblica de Obreiros, evento grandioso para glória de Deus. A preocupação com a preparação dos obreiros para crescimento da obra demonstra a dedicação dos pastores que passaram durante todos esses anos tiveram o cuidado com a obra do Senhor.

A evangelização cresceu gradualmente na região corumbaense e expandido para país vizinho que onde têm sido mantidos vários missionários na Bolívia. Sendo fundada em 08 de dezembro de 1962, a igreja de Puerto Quijarro, com a presença do pastor Túlio Barros Ferreira, a qual ficou denominada Asembleas de Dios Boliviana, sob a supervisão da Assembleia de Deus de Corumbá. Em 1965 fundaram a igreja de Porto Soares. Em 1968 chegara a Roboré e daí para frente à igreja foi avançando Bolívia. Durante vários anos a igreja esteve atuante na fronteira, mas a obra missionária foi sedimentada na gestão do pastor João Martins, e a secretaria de missões foram estruturados, os nossos missionários recebendo uma ajuda de custo e sendo cadastrados na Secretaria Nacional de Missões (SENAMI)[9], da CGADB[10].

A obra missionária avançou no prolongamento da ferrovia na até Santa Cruz de La Sierra metrópole da Bolívia as congregações foram consolidadas, como Posso Del Tigre, Chiochis, Paradero, Arroyo Concepcion, Três Cruzes.

A evangelização na cidade de Corumbá e região também cresceu de maneira vertiginosa do irmãos comprometidos com seara do Senhor.

Os pastores antecessores que passaram por Corumbá realizaram evangelismo até na parte rural, pois foram fundadas congregações nos assentamentos dedicação dos obreiros que se dispuseram a levar a palavra até os lugares mais longínquos do pantanal. Importante ressaltar que durante todos esses anos a obra do Senhor nunca parou sempre avançando, sendo acrescidas a cada dia a almas para reino do Senhor.

A cada dia que a igreja cresce aumenta o número de membros na igreja, o pastor vê a necessidade da ampliação do templo e no ano de 1999, através de sistema de mutirão com participação dos membros da Igreja, deu-se início a ampliação do Templo 
Central, e depois inaugurado com capacidade na época para 2 mil membros já se tornará maior templo do estado.

Em 2006 inicia-se a ampliação do Templo Central, com a cooperação de toda a Igreja através de mutirões e doações. O novo Templo tem capacidade ampliada para 5.000 pessoas sentadas. A igreja atualmente tem o maior templo do estado de Mato Grosso do Sul das ADs.

A preocupação com a pregação, ensino da palavra é firmada na Bíblia Sagrada, através do apoio do pastor João Martins, pastores e irmãos a igreja fundou e mantém em funcionamento uma Escola Teológica da Assembleia de Deus de Corumbá (ESTADEC)[11], saíram dessa Escola Teológica, vários ministros, evangelistas.

Também podemos relatar que a igreja tem passado por evolução no tocante às mudanças que estão acontecendo em quase todas as igrejas das Assembleias de Deus, a utilização da comunicação das redes sociais, bem como da mídia para divulgação do evangelho. A ampliação da comunicação respeito a utilizando de recursos para pregação do evangelho no uso dos meios como o rádio, televisão, carros de som e outros. O trabalho tem crescido com a evangelização e cruzadas evangelística a igreja a cada dia segue avançando e as almas chegando aos pés do Senhor.

Os trabalhos evangelísticos têm sido intensificado na região a igreja realiza constantemente cruzadas evangelísticas, cultos ao ar livre, visitas nos hospitais e o evangelismo pessoal. A realização de grandes eventos, festividade de grupos e trabalhos que confirmam o crescimento da igreja AD Corumbá.

A AD continua avançando comprometida com missão de levar a palavra como os pioneiros fizeram no passado, a igreja segue caminhando com projetos a serem realizados o pastor João Martins presidente da Igreja completa mais de duas décadas a frente da $A D$ Corumbá, enfrenta vários desafios para o crescimento da obra, término da construção do templo e novas congregações a serem construída. 
A igreja está completando 76 anos de existência e durante todo esse tempo de criação aconteceu várias lutas, mas agora consta com dezenas de congregações espalhadas pela região urbana, rural e fronteira, isso demonstra o quanto os seus líderes estiveram preocupados com a disseminação da palavra para alcançar as almas na região pantaneira.

Os pioneiros da igreja começaram o trabalho e a continuidade deve-se aos irmãos que permanecem realizando a obra do Senhor, isso é de fato foi o desejo dos pioneiros no legado que deixaram para os irmãos sucessores para realização da comissão inferida aos apóstolos e estendida até a volta do Senhor Jesus Cristo.

Uma nova geração de pastores e líderes tem se levantado na igreja, conforme relato do pastor presidente seu desejo é que cada dia se levantem mais obreiros para realizarem a obra do Senhor. Relacionado a isso pode ser verificado que AD Ministério de Belém de Corumbá é a maior Igreja Pentecostal na região, comprometida com a palavra de Deus e com a missão de ganhar almas para reino do Senhor.

O Senhor tem acrescido todos os dias almas para seu reino e os irmãos da AD de Corumbá são os instrumentos para promoverem a palavra. O compromisso de todos que passaram e realizaram a obra e tem sido notório como a igreja aumentou em número de membros. Conforme o Vice-Presidente Pr. João Lucas a AD de Corumbá tem renovado o número de jovens obreiros que são recrutados pelo Senhor Jesus Cristo e esses compromissados com a palavra, seguem na doutrina e ensino, conforme esses irmãos se apresentam para obra o crescimento permanece constante. Segundo o pastor que também é líder da União da Mocidade da Assembleia de Deus de Corumbá e Região (UMADCOR)[12] os jovens são os que darão a continuidade nos trabalhos a serem realizados e o crescimento será através dos novos irmãos que se achegam e apresentam-se para execução da missão imposta aos servos do Senhor (LUCAS,2017).

O líder da igreja Pr. João Martins esclarece que todo crescimento da igreja deve se ao cuidado dos irmãos com a obra, mas primeiramente ao Senhor Jesus que até aqui tem ajudado a liderança na condução de sua obra, o qual o pastor pode avaliar o seu 
trabalho com a seguinte frase: "Até aqui nos ajudou o Senhor" $1 \mathrm{Sm} \mathrm{7,12}$ (MARTINS,2017). De fato, o líder da igreja tem se destacado na região como um pastor visionário que segue a frente da igreja de Corumbá com autoridade e é o pastor com maior tempo na presidência da Igreja de Corumbá. A pesquisa que pode ser feita é que a $A D$ de Corumbá é uma igreja atuante, comprometida com evangelho e preocupada com crescimento das almas para reino do Senhor, Amém.

\section{CONSIDERAÇÕES FINAIS}

A Igreja Evangélica Assembleia de Deus em Corumbá, ao completar seus 76 anos de fundação, permanece na missão de divulgar o evangelho do Senhor Jesus Cristo, de forma genuína que surgiu devido o movimento pentecostal que é o fenômeno mais importante da história da igreja no século 20 segundo alguns teólogos. Sua história originou-se através do compromisso visionário de dois jovens missionários suecos que foram usados para fundarem a igreja Assembleia de Deus do Brasil.

A igreja evangélica Assembleia de Deus do Brasil na cidade de Corumbá-MS foi fundada em 1941, fato alcançado através dos pastores que lutaram incansavelmente para o crescimento do evangelho, de fato ela é a denominação da AD mais antiga na região Mato-grossense, e é muito atuante comprometida com a missão de levar a palavra do Senhor.

O crescimento é notório em toda região, isso é, através de trabalhos evangelísticos e assistenciais mantido pela AD de Corumbá, a preocupação de todos os pastores que passaram pela igreja foram fatores fundamentais como instrumentos nas mãos do Senhor para realizarem todas as atribuições de um Ministério Cristão que se preocupe com o próximo, seja no cuidado da Palavra do Senhor ou Serviço Social Assistencial. Ainda, a igreja tem uma escola evangélica em prédio próprio, com capacidade em ser transformada em um centro educacional. A Escola Evangélica é firmada nos princípios morais, éticos da família e ensino bíblico da palavra do Senhor, aonde as crianças aprendem a darem valor à palavra de Deus. Temos ainda a expansão na Bolívia aonde mantém o vínculo ministerial doutrinário e assistência financeira de dezenas de missionários para expansão do evangelho. 
Hoje, igreja dispõe de um templo reestruturado com capacidade estendida para cinco mil membros, ainda está sendo realizadas algumas finalizações na construção. A igreja tem aumentado números de congregações na região, obtendo um crescimento em número de irmão e irmãs, as novas congregações se espalham por toda área urbana e rural. Todo esforço alcançado durante seus anos, desde sua fundação deve se ao fato do empenho de irmãos e irmãs de levarem a palavra para região do pantanal, fez desta igreja uma referência perante a sociedade que sempre esteve atuante na assistência religiosa e filantrópica.

Por fim, torna-se importante salientar que todo esforço esmerados pelos seus pioneiros e líderes em terem edificado uma igreja na região de Corumbá, foi de grande valor, pois a cada dia tem sido acrescido o número de almas na Igreja Evangélica Assembleia de Deus Ministério Belém de Corumbá com todas as lutas enfrentadas permanece caminhando comprometida com a palavra do Senhor. Que o Senhor continue sustentando esse ministério e também todos os trabalhadores da sua obra para que abençoe esse trabalho e serviço até o dia da sua vinda, amém.

\section{REFERÊNCIAS}

ALENCAR, Gedeon Freire. Assembleia de Deus: origem, implantação e militância (1911-1946).

ARAUJO, Isael. 100 Acontecimentos que marcaram história das Assembleias de Deus. Rio de Janeiro: Arte Editorial, 2010.

Bíblia Sagrada -Almeida Edição Revista e Corrigida -Sociedade Bíblica do Brasil CPAD. 2010.

CGADB. A origem das assembleias de Deus no Brasil Disponível em: <http://www.editoracpad.com.br/assembleia/historia.php?i=2/htm> acesso em 10 de dez. de 2019. 
CONCEIÇÃO, Edir. História de MS é marcada pela efervescência política e movimentos sociais. Disponível em <http://www.ms.gov.br/a-historia-de-ms/.htm>. Acesso em 01 de jan. de 2020.

\section{Livros Atas do acervo da Igreja Evangélica AD Corumbá-MS.}

MARTINS, Pr. João. História da Igreja Assembleia de Deus de Corumbá: Depoimento. [15 de março, 2016]. Corumbá: TCC. Entrevista concedida a Marcelo Soares de Oliveira.

Memorial da Assembleia de Deus de Corumbá 64 anos, Corumbá: Acervo arquivo, 2005.

MENSAGEIRO DA PAZ. Rio de Janeiro: CPAD. Ano 80, n. 1.506, nov. 2010.

SOUZA, Pr. Rubens Siro. História da Assembleia de Deus no Estado de Mato Grosso. Cuiabá: Editora KCM. 2010.

VINGREN, Ivar. Gunnar Vingren: o diário do pioneiro, . 4. ed. Rio de Janeiro: CPAD, 1991

\section{APÊNDICE - REFERÊNCIAS DE NOTA DE RODAPÉ}

3. Igreja fronteiriça entre o Brasil e Bolívia.

4. Sanção presidencial de Ernesto Geisel para fundação do estado de Mato Grosso do Sul, esse processo ocorreu no dia de 11 de outubro de 1977. Fonte: brasilescola.uol.com.br/datas-comemorativas/mato-grosso-sulfundacao

5. Fundador da AD em Cochabamba-Bolívia e posteriormente presidiu a AD em São Cristovão-RJ.

6. Serviço de Assistência Social e Cultura da Igreja Evangélica Assembleia de Deus com a função de atender os membros e pastores das igrejas com serviços assistenciais. 
7. Abreviação da Assembleia de Deus.

8. Fundação do EUA, Fundação Health Care Ministries do ministério Bemhard Jhonson.

9. Sigla da Secretaria Nacional de Missões.

10. Sigla da Convenção Geral das Assembleias de Deus.

11. Sigla da Escola Teológica da Assembléia de Deus de Corumbá.

12. Sigla da União da Mocidade da Assembleia de Deus de Corumbá e Região é um conjunto de jovens de todas as igrejas de Corumbá e região.

Enviado: Setembro, 2019.

Aprovado: Março, 2020. 